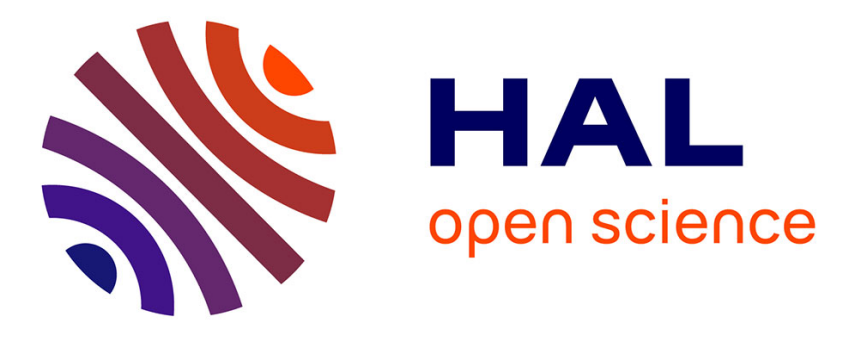

\title{
Domestic exposure to irritant cleaning agents and asthma in women
}

Pierre Lemire, Orianne Dumas, Sébastien Chanoine, Sofia Temam, Gianluca

Severi, Marie-Christine Boutron-Ruault, Jan-Paul Zock, Valérie Siroux, Raphaëlle Varraso, Nicole Le Moual

\section{To cite this version:}

Pierre Lemire, Orianne Dumas, Sébastien Chanoine, Sofia Temam, Gianluca Severi, et al.. Domestic exposure to irritant cleaning agents and asthma in women. Environment International, 2020, 144, pp.106017. 10.1016/j.envint.2020.106017 . inserm-02939405

\section{HAL Id: inserm-02939405 https://www.hal.inserm.fr/inserm-02939405}

Submitted on 15 Sep 2020

HAL is a multi-disciplinary open access archive for the deposit and dissemination of scientific research documents, whether they are published or not. The documents may come from teaching and research institutions in France or abroad, or from public or private research centers.
L'archive ouverte pluridisciplinaire HAL, est destinée au dépôt et à la diffusion de documents scientifiques de niveau recherche, publiés ou non, émanant des établissements d'enseignement et de recherche français ou étrangers, des laboratoires publics ou privés. 


\section{Domestic exposure to irritant cleaning agents and asthma in women}

Pierre Lemire ${ }^{1}$, Orianne Dumas ${ }^{1}$, Sébastien Chanoine ${ }^{2}$, Sofia Temam ${ }^{1,3}$, Gianluca Severi ${ }^{4}$, MarieChristine Boutron-Ruault ${ }^{4}$, Jan-Paul Zock ${ }^{5}$, Valérie Siroux ${ }^{2}$, Raphaëlle Varraso ${ }^{1}$, Nicole Le Moual ${ }^{1}$

${ }^{1}$ Université Paris-Saclay, UVSQ, Inserm, CESP, Equipe d'Epidémiologie Respiratoire Intégrative, 94807, Villejuif, France

${ }^{2}$ IAB, Team of Environmental Epidemiology Applied to Reproduction and Respiratory Health, INSERM U1209, University of Grenoble-Alpes, CHU de Grenoble - Grenoble, France

${ }^{3}$ MGEN Foundation for Public Health (FESP-MGEN), 75748, Paris, France

${ }^{4}$ Université Paris-Saclay, UVSQ, Inserm, CESP, Equipe Générations et Santé, 94805, Villejuif, France

${ }^{5}$ Barcelona Institute of Global Health (ISGlobal), Universitat Pompeu Fabra (UPF) - Barcelone,Spain

\section{Correspondence}

Marie-Christine Boutron-Ruault

Inserm U 1018 / CESP

Centre for Research in Epidemiology and Population Health

16, avenue Paul Vaillant Couturier

94807 Villejuif Cedex, France

Abstract word count: 303

Total word count (body of the manuscript): 3539

Numbers of tables and figures: 5

Number of references: 37 


\begin{abstract}
An adverse role of frequent domestic use of cleaning agents, especially in spray form, on asthma has been reported. However, sparse studies have investigated respiratory health effects of chronic domestic exposure to irritant cleaning agents. This study aims to investigate associations between weekly use of irritant domestic cleaning products and current allergic and non-allergic asthma in a large cohort of elderly women.
\end{abstract}

We used data from the Asthma-E3N nested case-control study on asthma ( $\mathrm{n}=19,404$ women, response rate: $91 \%, 2011$ ), in which participants completed standardized questionnaires on asthma and on the use of domestic cleaning products including irritants (bleach, ammonia, solvents and acids). Allergic multimorbidity in asthma was assessed from allergic-related medications recorded in drug refunds database. The association between use of irritants and current asthma was estimated by logistic regression (current vs. never asthma) and multinomial logistic regression (never asthma, non-allergic asthma, allergic asthma) adjusted on age, smoking status and body mass index (BMI).

In the 12,758 women included in the analysis (mean age: 70 years, current smokers: $4 \%, \mathrm{BMI} \geq 25$ $\mathrm{kg} / \mathrm{m}^{2}: 32 \%$, low education: $11 \%$, current asthma: $23 \%$ ), $47 \%$ reported weekly use of at least one irritant cleaning product at home. Weekly use of irritant products was associated with a higher risk of current asthma (adjusted Odds-Ratio: 1.17, 1.07-1.27). A statistically significant dose-response association was reported ( $\mathrm{p}$ trend $<0.0001$ ), with both the number of irritant products used weekly ( 1 irritant: 1.12, 1.021.23; 2 irritants: $1.21,1.05-1.39 ; 3$ irritants or more: $2.08,1.57-2.75)$ and the frequency of use (1-3 days/week:1.12, 1.02-1.23; 4-7 days/week = 1.41,1.22-1.64). A dose-response association was observed with the frequency of products used ( $p$ trend $<0.05)$, for both non-allergic $(4-7$ days/week, 1.27, 1.021.57) and allergic asthma (1.52; 1.27-1.82).

In conclusion, weekly use of common cleanings irritants was associated with an increased risk of current asthma, whatever the allergic status.

Key words (max 6): Asthma; asthma treatment; domestic cleaning; allergy; irritants 


\section{Introduction}

Adults spend most of their times inside buildings, at work or at home, and may be exposed to many chemicals(1), including cleaning agents(2). For infection control and hygiene purpose, the use of cleaning products and disinfectants has grown in the past decades, and especially in hospitals and at home. In two French studies, more than $70 \%$ of French women reported to clean their houses at least weekly whatever their age, and were more exposed than men to cleaning products $(3,4)$. Moreover, cleaning products have specific purposes (detergent, disinfectant), leading to a potential sequential use of several products to do all the cleaning tasks, and potentially to a mixture effect on health(5). Cleaning products are composed of many ingredients which may be airway irritants (bleach, ammonia, solvents, acids)(6) or allergens (perfumes such as limonene)(7,8), which induce or exacerbate asthma(2,9,10). Inversely, bleach may inactivate common indoor allergens, and the use of bleach has therefore been suggested to reduce the risk of sensitization to indoor allergens (11).

Asthma, a complex multifactorial disease for which environmental factors may play a key role in its development or exacerbation (12), is characterized by a strong phenotypic heterogeneity, and the allergic status is one of the main characteristic of disease heterogeneity. Non-allergic asthma is more frequent among patients with adult-onset asthma, which may be more severe and more frequent among women $(13,14)$. The underlying mechanisms in non-allergic asthma are still poorly characterized, and the potential role of the irritant cleaning products remain unknown. In epidemiological studies, the gold standard to evaluate the allergic status is based on biological tests (skin prick tests or specific IgEs), which are not usually available in large population-based surveys. Drug reimbursement databases may be an alternative to improve the asthma phenotypic characterization (15). However, to our knowledge such a database has never been used to evaluate the allergic status as an asthma multimorbidity in an epidemiological cohort.

Irritant-induced asthma has historically been described at work after an accidental massive exposure to irritants(6), and can sometimes be induced by the concomitant use of products that should not be mixed(16). Recent epidemiological findings suggested an association between chronic use of low to moderate chronic exposure to irritants and asthma $(6,17)$ though mechanisms remain unclear. Data on 
domestic use of cleaning products suggested an association with respiratory diseases, especially for sprayed products $(4,3,7)$. In a recent survey, daily use of disinfectants at home was associated with incident asthma(18). In addition, daily use of bleach at home was associated with non-allergic asthma(19), suggesting a role of chronic use of cleaning products in irritant-induced asthma outside professional context. The role of the number of irritant cleaning products used at home on asthma has not been evaluated. Although it has been suggested that chronic use of irritant cleaning products may induce asthma through a non-allergic mechanism rather than an allergic one(6), allergic status has rarely been examined in epidemiological studies on the association between irritant cleaning agents and asthma $(2,19)$.

The purpose of the present study was to investigate the association between chronic use of irritant cleaning products at home and current asthma in elderly women. The Asthma-E3N study represents a unique opportunity to evaluate allergy through drug refund data, and to test the hypotheses that chronic exposure to domestic irritant products increases the risk of asthma, and more specifically of non-allergic asthma, with a dose response relationship both for the frequency of use and the number of irritant products used.

\section{Material and methods}

\subsection{Study design and population}

The French E3N cohort (http://www.e3n.fr/) is an epidemiologic study, set up to study the role of nutrition and hormones on cancers and other chronic conditions, among 98,995 women, mainly teachers from the MGEN (Mutuelle Générale de l'Education Nationale) health Insurance plan(20). Various health data were recorded by biennial questionnaires. The E3N cohort also benefits from the access to drug refund data from the MGEN health insurance database since 2004.

Asthma-E3N is a case-control study on asthma nested in the E3N cohort and set up in 2011, among 21,300 women selected from the cohort. This study included all women who had ever had asthma (i.e., women who reported "asthma" at least once in the main E3N questionnaires between 1992 and $2005, \mathrm{n}=7,100$ ) and 14,200 aged-matched "women without asthma" (i.e., women who never reported " 
asthma" in the main E3N questionnaires). Standardized questionnaires were sent by mail to collect data on asthma, respiratory symptoms and treatments, and on frequency of use of domestic cleaning products, including four largely used types of irritants (bleach, ammonia, solvents and other acids). A total of 19,404 women responded to the questionnaire (participation rate: 91\%).

\subsection{Current asthma and allergic comorbidities}

Women who were defined as 'ever asthma' according to the E3N questionnaires or who answered positively in the Asthma-E3N questionnaire to at least one of the following two questions: 'Have you ever had asthma attacks?' and 'Have you ever had attacks of breathlessness at rest with wheeze?', were classified as 'ever asthma', as suggested by the British Medical Research Council (BMRC). Women who never reported 'ever asthma' in E3N questionnaires and who answered negatively to the asthma questions in Asthma-E3N were classified as 'never asthma'. Among women with 'ever asthma', those who reported asthma attacks, use of asthma treatment or at least one out of five asthma symptoms (wheezing, woken up with a feeling of chest tightness, attack of shortness of breath at rest, attack of shortness of breath after exercise, woken up by an attack of shortness of breath) in the last twelve months were defined as 'current asthma'. Current asthma definition is very close to the one used in the European Community Respiratory health Survey (ECRHS)(21) and the French EGEA survey $(3,4)$.

The MGEN drug administrative database allows to extract refunds for anti-allergic (allergic rhinitis (AR), atopic dermatitis and allergic conjunctivitis) treatments in the 12 months before the Asthma-E3N questionnaire. For each participant, assessment of anti-allergic treatments was based on the refund database records, of specific therapeutic indications for one or several of these three allergic comorbidities, according to the 5-level ATC codes (22) listed in the 'Thériaque' database (http://www.theriaque.org). The list of used ATC codes is available in supplementary materials (table S1). Subsequently, a 3-level asthma phenotype was defined: never asthma (reference group), and allergic (at least one anti-allergic treatment recorded in the last 12 months) current asthma, and non-allergic (no anti-allergic treatment recorded) current asthma. 
2.3 Domestic use of cleaning products

Frequency of use of cleaning products was reported in a specific questionnaire in 4 classes (never, less than once a week, 1-3 days a week, and 4-7 days a week (daily use)), as previously described(4), for the four following irritants: bleach, ammonia, solvents and acids. A participant was considered weekly exposed to an irritant if she reported its use at least once a week. Frequency and the number of irritant products used weekly were classified as follows: a) frequency of use, defined in 3 classes ( 0 : never or less than once a week for the 4 irritants; 1 : 1-3 days per week; $2: 4-7$ days per week (daily) for at least one irritant), b) number of products used, defined in 4 classes (0: never or less than once a week for the 3 irritants, 1: 1 irritant used weekly; 2: two irritants used weekly; 3: at least three irritants used weekly) or in 3 classes, after combining the 2 last classes (at least 2 irritants used weekly) to avoid small sample. In addition, a participant was considered as a 'spray user' (weekly use; yes/no) if she reported weekly use of at least one of the following products in spray form: furniture, glass, floor, oven, air freshener, insecticide or others.

\subsection{Covariates}

Age was considered as a continuous variable and smoking status as a 3-classes categorical variable: "never smoker", "past smoker" and "current smoker". Body Mass Index (BMI ; <20, [20-25[, [25-30[, $\geq 30 \mathrm{~kg} / \mathrm{m}^{2}$ ) and educational level ( $<$ high school diploma, high school to 2-level university diploma, 3-level or 4-level university diploma, $>5$-level university diploma) were defined by 4-classes categorical variables. Use of inhaled corticosteroids (ICS), an anti-inflammatory treatment, in the past 12 months was assessed from the MGEN drug administrative database (see online supplement), as previously defined(23). Household help was defined as a binary variable, following the answer to "Do you get help to clean at home?".

\subsection{Statistical Analysis}

Associations between the use of domestic irritant cleaning products and current asthma and the 3-level asthma outcome accounting for anti-allergic treatment were evaluated by logistic and multinomial regression models, respectively. In addition, as allergic and non-allergic asthma may not 
be well separated disease entities, a stratified analysis on allergy was conducted as previously suggested(24). All analyses were adjusted for age, smoking status and BMI $(3,4,19)$.

Further analyses were conducted to address the potential role of effect-modifiers in the irritant use and current asthma association, including household help, spray use and ICS use. We hypothesized a stronger association among participants without household help (less misclassification errors) (4) and among those using sprays (known to be associated with an increased risk of asthma (25)), and a lower association among those using ICS (an anti-inflammatory treatment) (4).

In addition, several sensitivity analyses were performed to test the robustness of our results according to the definition of the allergic status, by using first a more specific definition based on at least 2 refunds in the last year (instead of 1), and secondly a more sensitive definition by adding ATC codes with less specific therapeutic indications than those selected in the main analysis (see supplementary file, Table S2) and thirdly, using a definition based on allergic diseases as reported by questionnaire instead of assessed through drug refund data (see supplementary file).

All statistical analyses were performed using SAS version 9.3 (SAS Institute Inc., Cary, NC, USA).

\section{Results}

Figure 1

A total of 12,758 women, 2,869 with current asthma and 9,889 without asthma, were included in the analysis (Figure 1), after exclusion of women with missing or incoherent data for ever asthma $(n=2,054)$, household help $(n=1,213)$ or domestic exposure $(n=547)$. In addition, 2,832 women without current asthma or with missing values for current symptoms were excluded from the analysis. Excluded women because of missing data were older, more often overweighted and current smokers, had a lower educational level and used more cleaning sprays and irritants, as compared to included women (Table S3). Excluded women because of incoherent asthma data were more often ever smokers, had a higher educational level, more allergic comorbidities and more often refunds of ICS in the last 12 months, as compared to included women. 
Women were aged on average 70 , a third of them were overweight (BMI $\geq 25 \mathrm{~kg} / \mathrm{m}^{2}$ ), half of them never smoked and half of them reported the use of at least one irritant cleaning product weekly (Table 1). Women with current asthma had a higher BMI, were more often smokers, had more often help for their cleaning tasks, used more cleaning irritants and sprays, had more often allergic rhinitis or allergic comorbidities and ICS refunds than women who never had asthma $(\mathrm{p}<0.0001)$.

\section{Table 1}

\subsection{Use of irritant cleaning products and risk of current asthma}

Weekly use of at least one irritant cleaning product at home was associated with a higher risk of current asthma (adjusted Odds-Ratio (ORa) [95\%CI]: 1.17 [1.07-1.27], Table 2). A dose-response relationship was observed ( $\mathrm{p}$ trend $<0.0001$ ): the risk of current asthma increased with increased number of irritant products used, and increased frequency of use. Analyses stratified on household help (supplementary material, Table S4) or spray use (Table S5) or considering ICS refunds (Table S6) led to statistically significant associations within each group and no statistically significant interactions were reported. Nevertheless, associations were slightly stronger among women without household help (Table S4), women regularly using sprays (Table S5) and asthmatics without ICS refund (Table S6) in the last 12 months.

\section{Table 2}

3.2 Use of irritant cleaning products and risk of allergic and non-allergic asthma

Associations between weekly use of irritants and current asthma were statistically significant and of similar magnitude for allergic (1.19 [1.07-1.32]) and non-allergic (1.15 [1.02-1.30]) asthma. For non-allergic asthma (Figure 2), no trend was observed according to the number of products used weekly (1 irritant: 1.15 [1.01-1.32]); $\geq 2$ irritants: 1.13 [0.93-1.37]), whereas the strength of the association increased with the frequency of use (1-3 days/week: 1.12 [0.99-1.28]; 4-7 days/week: 1.27 [1.02-1.57]; $\mathrm{p}$ for trend $<0.02$ ). By contrast, associations with allergic asthma significantly increased with both 
product uses, as numbers (1 irritants: 1.09 [0.97-1.23]; at least 2 irritants: 1.46 [1.25-1.71]) or frequency (1-3 days/week: 1.12 [1.00-1.25]; 4-7 days/week: 1.52[1.27-1.82]); $\mathrm{p}$ trend $<0.001$ for both. Sensitivity analyses varying the sensitivity or specificity of the allergic definition (supplementary material, table S7) showed similar results. When using questionnaire-based allergic definition, no associations was observed between weekly use of irritants and asthma without allergic rhinitis, either considering the number of products or the frequency of use (supplementary material, figure S1). By contrast, an increased risk of asthma with allergic rhinitis was observed with the weekly use of irritants, either in number $(1$ irritant $=1.27[1.11-1.44]$; at least 2 products $=1.62[1.37-1.93])$ or frequency $(1-3$ days /week=1.30 [1.15-1.47]; 4-7 days/week=1.64 [1.35-2.01]), with significant trends $(\mathrm{p}<0.0001)$.

Figure 2

In addition, analyses stratified on allergic status was performed on 7829 non-allergic (including 1171 current asthma) and 4445 allergic (including 1587 current asthma) participants. Associations between weekly use of irritants and current asthma were of similar magnitude for non-allergic and allergic participants but non-significant for allergic participants $(\mathrm{p}=0.15$; Table 3$)$. Among both nonallergic and allergic participants, the strength of the association increased with the number and the frequency of use ( $\mathrm{p}$ trend $<0.02$ for both).

\section{Table 3}

\section{Discussion}

Our study reported an increased risk of current asthma among weekly users of irritant cleaning products at home, and a dose-response relationship according to both frequency and number of products used. Similar associations were observed whatever the allergic status. Consistent associations were observed in several sensitivity analyses, underlying the robustness of our findings.

Our results are consistent with previous studies on both occupational and domestic use of bleach. Literature has shown an increased risk of asthma for occupational exposure to bleach(10), but research on domestic use of cleaning products is much more limited, especially for irritants. Noteworthy, our 
study showed an increased risk of current asthma among irritant users even for a low number of products weekly used, whereas previous studies reported association only for daily (4-7 days/week) use of irritants at home $(7,18,26)$. In the European respiratory ECRHSII cohort, a significant association between daily use of bleach and incidence of asthma symptoms was observed (26) whereas no significant association with incident asthma was observed for weekly use of bleach (7). Among young adults in Germany, an association was observed between daily use of disinfectants, which are possibly mainly irritants (18), and incident asthma among a young population (19-24 years old; 55,6\% women). Overall, our results are consistent with previous reports in the professional setting, suggesting an association between low chronic exposure to irritants and asthma (17).

Our results do not support the hypothesis that irritant cleaning products are specifically associated to non-allergic asthma by contrast to some previous studies conducted in younger populations $(11,19,26)$. In ECRHS, participants who use bleach to clean their homes were less likely to be atopic (26). In addition, in the EGEA cohort, daily use of bleach by women at home was associated with nonallergic current asthma(19). Although it has been hypothesized that the use of bleach could inactivate allergens (thus leading to a lower sensitization risk, among subjects with asthma), those with allergic asthma may follow allergens prevention measures and may be more prone using bleach to inactivate allergens. In addition, cleaning products available at retails have a very complex and diverse composition (27), including perfumes(28), considered as sensitizers (10) that could partly explain the association with allergic asthma. Finally, the underlying mechanism in irritant-induced asthma is unknown(6). Different pro-inflammatory mechanisms may be involved in asthma due to low-dose chronic exposure $(2,10)$, including a role of oxidative stress, neutrophilic inflammation, repeated stimulation of local neural endings or the TRP receptor family. Chronic exposure to irritants could also cause damage to the lung epithelial barrier, which could lead to higher systemic exposure to airway allergens, as it was suggested in a study on formaldehyde exposure and mite allergen sensitization(29).

One of the strengths of our analysis is that our study benefited for the first time in the literature from data of a very large population $(n>12000)$ enriched in asthmatics, including one fourth women with current asthma, allowing for analyses on specific subpopulations to further investigate the association. Although we a priori hypothesized that the association would be stronger among those 
without household help, we observed that associations were similar whatever the household help status. One possible explanation is that household helpers used the products mainly in the presence of the participants which is likely in our population of elderly women (mean age around 70, in 2011). Such passive exposure may not be negligible (27) and may vary according to the population and the time people spend at home. It might explain why no association had been reported in a recent study in adolescents (30) whereas we report an association in our elderly population. It is also possible that even with household help, there is still an active use of irritant cleaning products. The association between spray use and asthma has been suggested by several studies $(4,3,7)$, and may explain in part observed associations of current asthma with irritants. However, in our study, the reported association between the weekly use of irritants and current asthma was independent of spray use. In addition, as expected, we reported an association slightly less pronounced between irritants and current asthma among asthmatics with refunded ICS (anti-inflammatory). Finally, associations remained significant in various sensitivity analyses suggesting the robustness of our findings.

Access to the exhaustive drug refund data and epidemiological standardized questionnaires for all E3N participants is another strength of the study. For the first time in the literature, we used such a database to evaluate the allergic status, by identifying reimbursement of treatment specifically delivered for allergic rhinitis, conjunctivitis or dermatitis. Studying allergic asthma as a specific phenotype or not (stratified analysis) led to the same conclusion. To evaluate the potential impact of misclassification errors in the allergic status assessment in our findings, we performed sensitivity analyses by varying the specificity of the allergic definition. The magnitude of associations increased with the number of refunds (higher specificity) and decreased when including nonspecific ATC codes (lower specificity), which is consistent with the previous recommendations on the importance to favor specificity over sensitivity in etiological research (31). When we evaluated the allergic status by questionnaire, based on the report of allergic rhinitis (32), i.e not considering conjunctivitis or dermatitis in the definition, significant associations were only observed for allergic asthma. We acknowledge that a method of reference, such as IgE levels or skin prick tests, both unavailable in $\mathrm{E} 3 \mathrm{~N}$, would have been more appropriate to distinguish allergic to non-allergic asthma. 
Our study also has limitations. The Asthma-E3N population is constituted of mostly educated older women which limits generalizability of the findings. Women included in the E3N cohort are contributing members of the MGEN health insurance plan, which covered mostly workers or their spouses from the state education field. Around $90 \%$ of the participants had at least a high school diploma, whereas only $18 \%$ of women aged more than 65 years old had this diploma level in 2010 in France (33). Studies in other age or socio-economic categories may be necessary to further investigate the association between domestic use of irritants and asthma. In addition, drug refunds data do not systematically reflect drug intake, nor the windows of exposure $(15,23)$. Although over-the-counter (OTC) drugs could not be recorded, it is expected to have little impact on our results because such drugs are marketed only since 2008 in France (34), and because a study estimated that only 14\% of French people with allergic rhinitis only uses OTC antihistamine drugs (35). In addition, assessing exposure to irritant cleaning product in epidemiological settings is not trivial. In our study, we considered cleaning products by unique components hypothesized to be irritants. But some of the ingredients of cleaning products may react with other chemicals such as chloramines $(11,36)$, and mixing bleach with acids produces chlorine, a potent airway irritant $(11,16)$. More objective methods to assess exposure to cleaning products may be helpful in epidemiologic studies to handle the diversity of the products used and potentially study not only groups of products, but their precise ingredients (37).

\section{Conclusion}

Domestic irritant cleaning product use was associated with an increased risk of current asthma in an elderly population. Associations were statistically significant with exposure as low as weekly exposure to one irritant and the strength of associations increased in a dose-dependent manner with both the frequency and the number of products used. Analyses making a distinction between allergic and non-allergic asthma, based on drug refunds for allergic rhinitis, dermatitis or conjunctivitis, showed associations in both asthma phenotypes. Further studies based on refined asthma phenotypes or endotypes are warranted to further investigate the underlying mechanisms in the association between irritant cleaning agents and asthma. 


\section{Declaration of competing interest}

The authors declare that they have no known competing financial interests or personal relationships that could have appeared to influence the work reported in this paper.

\section{Acknowledgements}

The authors are grateful for the help received from Marie Fangon, Maryvonne Niravong, Lyan Hoang (Inserm, CESP, Centre for Research in Epidemiology and Population Health, UMRS 1018, Exposome, Inheritance, Cancer and Health team, Villejuif, France) for the implementation of the study. They are indebted to all the participants for their high involvement in the E3N study, and without whom the study would not have been possible.

\section{Funding sources}

This work was supported by a grant of The Institut pour la Recherche en Santé Publique (IRESP), and of the joint help of Direction Générale de la Santé (DGS), Mission recherche de la Direction de la recherche, des études, de l'évaluation et des statistiques (Mire-DREES), Caisse nationale d'assurance maladie des travailleurs salariés (CNAMTS), Régime Social des Indépendants (RSI) \& Caisse nationale de solidarité pour l'autonomie (CNSA).

The E3N study is supported by the Mutuelle Générale de l'Education Nationale (MGEN); the French League against Cancer (LNCC); Gustave Roussy; and the French Research Agency (ANR grant, ANR-10-COHO-0006). 
References

1. Pelletier M, Glorennec P, Mandin C, Le Bot B, Ramalho O, Mercier F, et al. Chemical-bychemical and cumulative risk assessment of residential indoor exposure to semivolatile organic compounds in France. Environ Int. 2018;117:22-32.

2. Dumas O, Le Moual N. Damaging effects of household cleaning products on the lungs. Expert Rev Respir Med. 2020 Jan;14(1):1-4.

3. Le Moual N, Varraso R, Siroux V, Dumas O, Nadif R, Pin I, et al. Domestic use of cleaning sprays and asthma activity in females. Eur Respir J. 2012 Dec;40(6):1381-9.

4. Bédard A, Varraso R, Sanchez M, Clavel-Chapelon F, Zock J-P, Kauffmann F, et al. Cleaning sprays, household help and asthma among elderly women. Respir Med. 2014 Jan;108(1):171-80.

5. Dimitroulopoulou C, Lucica E, Johnson A, Ashmore MR, Sakellaris I, Stranger M, et al. EPHECT I: European household survey on domestic use of consumer products and development of worstcase scenarios for daily use. Sci Total Environ. 2015 Dec 1;536:880-9.

6. Vandenplas O, Wiszniewska M, Raulf M, de Blay F, Gerth van Wijk R, Moscato G, et al. EAACI position paper: irritant-induced asthma. Allergy. 2014 Sep;69(9):1141-53.

7. Zock J-P, Plana E, Jarvis D, Antó JM, Kromhout H, Kennedy SM, et al. The use of household cleaning sprays and adult asthma: an international longitudinal study. Am J Respir Crit Care Med. 2007 Oct 15;176(8):735-41.

8. Wolkoff P, Nielsen GD. Effects by inhalation of abundant fragrances in indoor air - An overview. Environ Int. 2017 Apr;101:96-107.

9. Tarlo SM, Lemiere C. Occupational asthma. N Engl J Med. 2014 Feb 13;370(7):640-9.

10. Folletti I, Siracusa A, Paolocci G. Update on asthma and cleaning agents. Curr Opin Allergy Clin Immunol. 2017 Apr;17(2):90-5.

11. Nickmilder M, Carbonnelle S, Bernard A. House cleaning with chlorine bleach and the risks of allergic and respiratory diseases in children. Pediatr Allergy Immunol. 2007 Feb;18(1):27-35.

12. Cabieses B, Uphoff E, Pinart M, Antó JM, Wright J. A systematic review on the development of asthma and allergic diseases in relation to international immigration: the leading role of the environment confirmed. PLoS ONE. 2014;9(8):e105347.

13. Wenzel SE. Asthma: defining of the persistent adult phenotypes. Lancet. 2006 Aug 26;368(9537):804-13.

14. Moore WC, Meyers DA, Wenzel SE, Teague WG, Li H, Li X, et al. Identification of Asthma Phenotypes Using Cluster Analysis in the Severe Asthma Research Program. Am J Respir Crit Care Med. 2010 Feb 15;181(4):315-23.

15. Chanoine S, Pin I, Sanchez M, Temam S, Pison C, Le Moual N, et al. Asthma Medication Ratio Phenotypes in Elderly Women. J Allergy Clin Immunol Pract. 2018 Jun;6(3):897-906.e5.

16. Das R, Blanc PD. Chlorine gas exposure and the lung: a review. Toxicol Ind Health. 1993 Jun;9(3):439-55.

17. Dumas O, Le Moual N. Do chronic workplace irritant exposures cause asthma? Curr Opin Allergy Clin Immunol. 2016 Apr;16(2):75-85. 
18. Weinmann T, Gerlich J, Heinrich S, Nowak D, Mutius E von, Vogelberg C, et al. Association of household cleaning agents and disinfectants with asthma in young German adults. Occup Environ Med. 2017 Sep;74(9):684-90.

19. Matulonga B, Rava M, Siroux V, Bernard A, Dumas O, Pin I, et al. Women using bleach for home cleaning are at increased risk of non-allergic asthma. Respir Med. 2016 Aug;117:264-71.

20. Clavel-Chapelon F, E3N Study Group. Cohort Profile: The French E3N Cohort Study. Int J Epidemiol. 2015 Jun;44(3):801-9.

21. Cazzoletti L, Marcon A, Janson C, Corsico A, Jarvis D, Pin I, et al. Asthma control in Europe: a real-world evaluation based on an international population-based study. J Allergy Clin Immunol. 2007 Dec;120(6):1360-7.

22. WHO Collaborating Centre for Drug Statistics Methodology. Guidelines for ATC classification and DDD assignment, 2020. Oslo, 2019;

23. Sanchez M, Varraso R, Bousquet J, Clavel-Chapelon F, Pison C, Kauffmann F, et al. Perceived 10-year change in respiratory health: reliability and predictive ability. Respir Med. 2015 Feb;109(2):188-99.

24. Pekkanen J, Lampi J, Genuneit J, Hartikainen A-L, Järvelin M-R. Analyzing atopic and non-atopic asthma. Eur J Epidemiol. 2012 Apr;27(4):281-6.

25. Siracusa A, De Blay F, Folletti I, Moscato G, Olivieri M, Quirce S, et al. Asthma and exposure to cleaning products - a European Academy of Allergy and Clinical Immunology task force consensus statement. Allergy. 2013 Dec;68(12):1532-45.

26. Zock J-P, Plana E, Antó JM, Benke G, Blanc PD, Carosso A, et al. Domestic use of hypochlorite bleach, atopic sensitization, and respiratory symptoms in adults. J Allergy Clin Immunol. 2009 Oct;124(4):731-738.e1.

27. Bello A, Quinn MM, Perry MJ, Milton DK. Quantitative assessment of airborne exposures generated during common cleaning tasks: a pilot study. Environ Health. 2010 Nov 30;9:76.

28. Wei W, Boumier J, Wyart G, Ramalho O, Mandin C. Cleaning practices and cleaning products in nurseries and schools: to what extent can they impact indoor air quality? Indoor Air. 2016 Aug;26(4):517-25.

29. Casset A, Marchand C, Purohit A, Le Calve S, Uring-Lambert B, Donnay C, et al. Inhaled formaldehyde exposure: effect on bronchial response to mite allergen in sensitized asthma patients. Allergy. 2006;(11):1344.

30. Bukalasa JS, Brunekreef B, Koppelman GH, Vonk JM, Gehring U. Use of cleaning agents at home and respiratory and allergic symptoms in adolescents: The PIAMA birth cohort study. Environ Int. 2019;128:63-9.

31. Le Moual N, Kennedy SM, Kauffmann F. Occupational exposures and asthma in 14,000 adults from the general population. Am J Epidemiol. 2004 Dec 1;160(11):1108-16.

32. Burte E, Bousquet J, Siroux V, Just J, Jacquemin B, Nadif R. The sensitization pattern differs according to rhinitis and asthma multimorbidity in adults: the EGEA study. Clin Exp Allergy. 2017 Apr;47(4):520-9. 
33. FOR2 - Population non scolarisée de 15 ans ou plus par sexe, âge et diplôme le plus élevé en 2010 - France métropolitaine -Diplômes - Formation en 2010 | Insee [Internet]. [cited 2019 Aug 29]. Available from: https://insee.fr/fr/statistiques/2044324?sommaire=2132843\&geo=METRO-1

34. Décision du 1er juillet 2008 portant inscription sur la liste des médicaments de médication officinale mentionnée à l'article R. 5121-202 du code de la santé publique | Legifrance [Internet]. [cited 2020 Jun 5]. Available from: https://www.legifrance.gouv.fr/eli/decision/2008/7/1/SJSM0820423S/jo

35. Zuberbier T. Undertreatment of rhinitis symptoms in Europe: findings from a cross-sectional questionnaire survey. Allergy. 2007 Sep;62(9):1057-63.

36. Carder M, Seed MJ, Money A, Agius RM, van Tongeren M. Occupational and work-related respiratory disease attributed to cleaning products. Occup Environ Med. 2019;76(8):530-6.

37. Quinot C, Amsellem-Dubourget S, Temam S, Sevin E, Barreto C, Tackin A, et al. Development of a bar code-based exposure assessment method to evaluate occupational exposure to disinfectants and cleaning products: a pilot study. Occup Environ Med. 2018 May 14; 
Figure 1. Flowchart for the selected population.

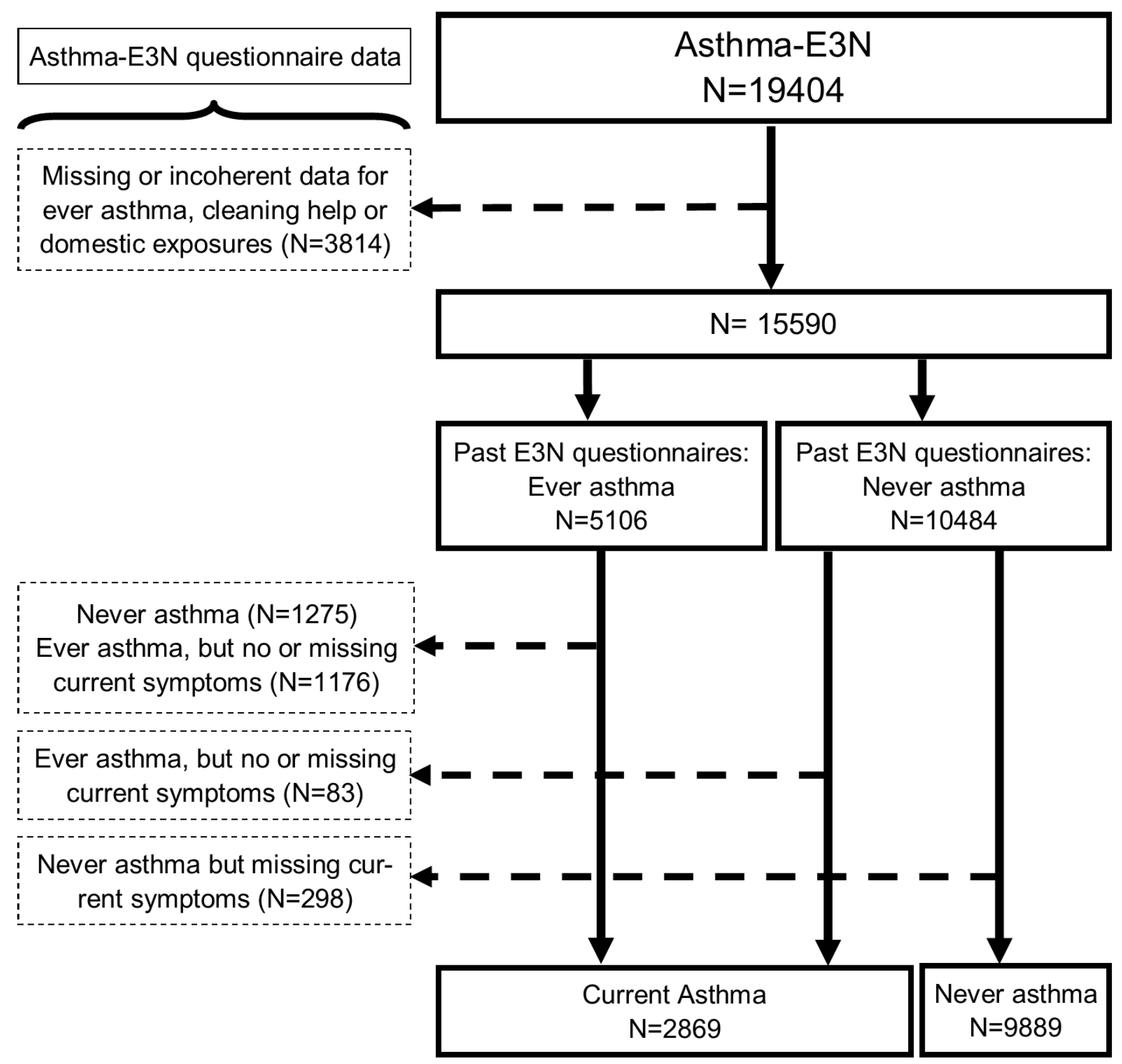


Table 1- Population characteristics according to current asthma status among 12758 women participating in the Asthma-E3N study.

\begin{tabular}{|c|c|c|c|}
\hline & $\begin{array}{r}\text { Never } \\
\text { asthma }\end{array}$ & $\begin{array}{r}\text { Current } \\
\text { asthma }\end{array}$ & p-value ${ }^{a}$ \\
\hline $\mathbf{N}$ & 9889 & 2869 & \\
\hline Age (years), mean \pm s.d & $69.7 \pm 6.1$ & $69.5 \pm 5.9$ & 0.69 \\
\hline BMI (Body Mass Index), n (\%) & 9889 & 2869 & $<0.0001$ \\
\hline$<20$ & $1299(13.1)$ & $289(10.1)$ & \\
\hline$[20-25[$ & $5653(57.2)$ & $1421(48.5)$ & \\
\hline$[25-30[$ & $2348(23.7)$ & $816(28.4)$ & \\
\hline$\geq 30$ & $589(6.0)$ & $343(12.0)$ & \\
\hline Smoking status, n (\%) & 9853 & 2851 & $<0.0001$ \\
\hline Never smoker & $5406(54.9)$ & $1423(50.0)$ & \\
\hline Ex-smoker & $4021(40.8)$ & $1307(45.8)$ & \\
\hline Current smoker & $426(4.3)$ & $121(4.2)$ & \\
\hline Educational level, n (\%) & 9513 & 2754 & 0.1224 \\
\hline$<$ high school diploma & $1025(10.8)$ & $286(10.4)$ & \\
\hline High school to 2-level university diploma & $4989(52.4)$ & $1396(50.7)$ & \\
\hline 3-level or 4-level university diploma & $1826(19.2)$ & $529(19.2)$ & \\
\hline >5-level university diploma & $1673(17.6)$ & $543(19.7)$ & \\
\hline Household help, n (\%) & 9889 & 2869 & \\
\hline Yes & $3794(38.4)$ & $1328(46.3)$ & $<0.0001$ \\
\hline Weekly irritant ${ }^{\mathrm{b}}$ use, $n(\%)$ & 9550 & 2776 & \\
\hline Yes & $4364(45.7)$ & $1393(50.2)$ & $<0.0001$ \\
\hline Weekly spray use, n (\%) & 9644 & 2791 & \\
\hline Yes & $2140(22.2)$ & $726(26.0)$ & $<0.0001$ \\
\hline Allergic rhinitis, current (questionnaire), n (\%) & 8330 & 2260 & \\
\hline Yes & $1384(16.6)$ & $1317(58.3)$ & $<0.0001$ \\
\hline $\begin{array}{l}\text { Treatments for allergic diseases (refund database), } \\
12 \text { months, } n(\%)\end{array}$ & 9889 & 2869 & \\
\hline Yes & $2967(30.0)$ & $1648(57.4)$ & $<0.0001$ \\
\hline ICS $^{\mathrm{c}}$ use (refund database), 12 months, $\mathrm{n}(\%)$ & 9889 & 2869 & \\
\hline Yes & $459(4.6)$ & $1366(47.6)$ & $<0.0001$ \\
\hline \multicolumn{4}{|c|}{$\begin{array}{l}{ }_{b}^{a} \text { p-value of the chisq test for difference between never asthma and current asthma group } \\
b \text { domestic irritant cleaning products used, grouping } 4 \text { categories: ammonia, bleach, solvents } \\
\text { and acids } \\
{ }^{c} \text { at least one ICS refunded in the last } 12 \text { months (ATC codes: R03BA, R03AK06-13, }\end{array}$} \\
\hline
\end{tabular}


Table 2- Associations between domestic irritants use, in frequency or number per week, and current asthma

\begin{tabular}{|c|c|c|c|c|c|c|}
\hline & $\mathrm{n}$ & $\begin{array}{l}\text { Never } \\
\text { asthma, \% } \\
\mathrm{n}=9550\end{array}$ & $\begin{array}{l}\text { Current } \\
\text { asthma, \% } \\
\mathrm{n}=2776\end{array}$ & $\begin{array}{l}\text { Crude OR } \\
\text { (IC à 95\%) }\end{array}$ & $\mathrm{n}$ & $\begin{array}{l}\text { Adjusted } \mathrm{OR}^{\mathrm{a}, *}, \\
\text { (IC à } 95 \% \text { ) }\end{array}$ \\
\hline \multicolumn{7}{|c|}{ At least 1 irritant $^{b} /$ week } \\
\hline No (reference) & 6569 & 54.3 & 49.8 & 1 & 6551 & 1 \\
\hline Yes & 5757 & 45.7 & 50.2 & $1.20[1.10-1.30]$ & 5723 & $1.17[1.07-1.27]$ \\
\hline \multicolumn{7}{|c|}{ Number of irritants ${ }^{b}$ used / week } \\
\hline 1 & 4244 & 34.1 & 35.6 & $1.14[1.04-1.25]$ & 4223 & $1.12[1.02-1.23]$ \\
\hline 2 & 1283 & 10.1 & 11.5 & $1.25[1.08-1.43]$ & 1274 & $1.21[1.05-1.39]$ \\
\hline$\geq 3$ & 230 & 1.5 & 3.1 & $2.20[1.67-2.89]$ & 226 & $2.08[1.57-2.75]$ \\
\hline$p$ for trend & & & & $<0.0001$ & & $<0.0001$ \\
\hline \multicolumn{7}{|c|}{ Frequency of irritants ${ }^{b}$ used / week } \\
\hline $1-3 d /$ week & 4705 & 37.8 & 39.6 & $1.14[1.04-1.25]$ & 4679 & $1.12[1.02-1.23]$ \\
\hline 4-7d/week & 1052 & 7.9 & 10.6 & $1.46[1.26-1.69]$ & 1044 & $1.41[1.22-1.64]$ \\
\hline$p$ for trend & & & & $<0.0001$ & & $<0.0001$ \\
\hline
\end{tabular}

${ }^{a}$ adjusted for age, smoking status and BMI

${ }^{b}$ domestic irritant cleaning products used, grouping 4 categories: ammonia, bleach, solvents and acids

* $n=12,274$; 52 excluded for missing smoking status data 
Figure 2. - Associations between weekly use of irritants at home, in frequency or number per week, and current asthma with or without allergic comorbidities.

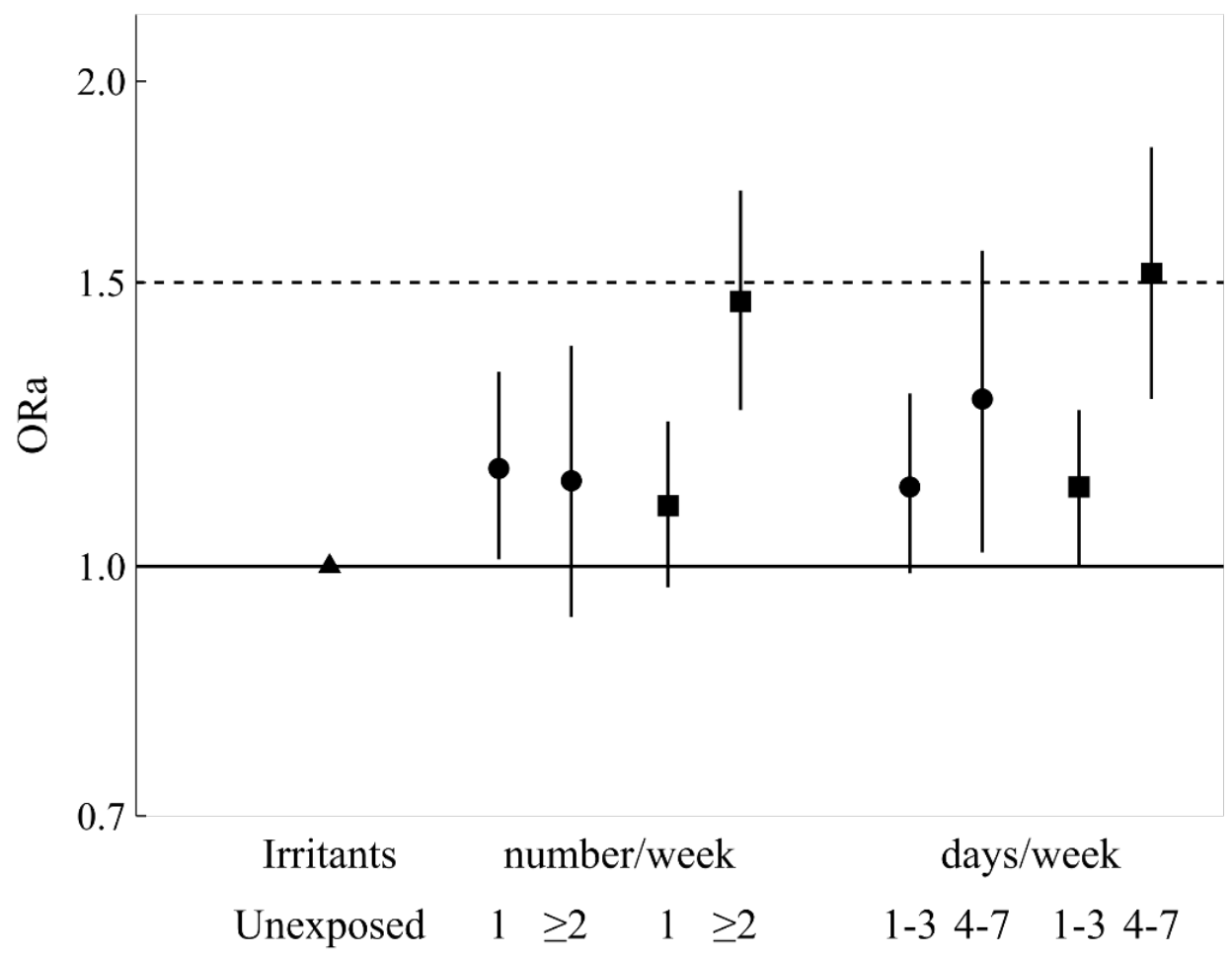

Current asthma without anti-allergic treatment (last 12 months) Current asthma with anti-allergic treatment (last 12 months)

ORa Odds Ratios adjusted for age, smoking status and BMI 
Table 3

Adjusted associations between domestic irritants use and current asthma, stratified on allergic status

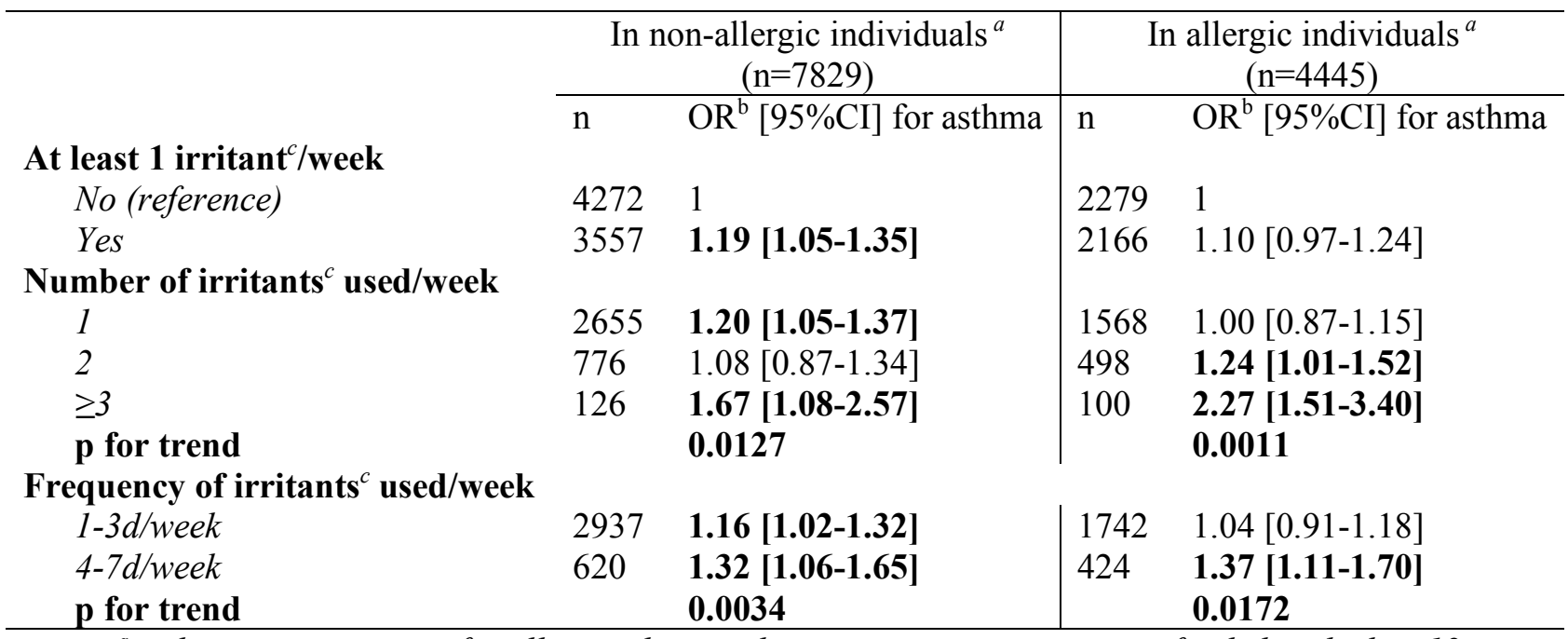

${ }^{a}$ at least one treatment for allergic rhinitis, dermatitis or conjunctivitis refunded in the last 12 months

${ }^{b}$ adjusted for age, smoking status and BMI

${ }^{c}$ domestic irritant cleaning products used, grouping 4 categories: ammonia, bleach, solvents and acids 